\title{
Large volume infusions of hydroxyethyl starch during cardiothoracic surgery may be associated with postoperative kidney injury: propensity-matched analysis
}

Wataru Matsunaga ${ }^{1}$, Masamitsu Sanui ${ }^{1 *}$ D, Yusuke Sasabuchi ${ }^{2}$, Yasuma Kobayashi ${ }^{1}$, Asuka Kitajima', Fumitaka Yanase ${ }^{1}$, Yutaka Takisawa ${ }^{1}$ and Alan Kawarai Lefor ${ }^{3}$

\begin{abstract}
Background: The safety of intraoperative administration of hydroxyethyl starch (HES) has been debated. We hypothesized that intraoperative use of HES is associated with postoperative acute kidney injury (AKI) following cardiopulmonary bypass (CPB).
\end{abstract}

Materials and methods: Patients who underwent cardiothoracic surgery using CPB between 2007 and 2014 were retrospectively reviewed. The incidence of AKI within 7 days after surgery, defined by the Kidney Disease Improving Global Outcome criteria, was compared for patients who did or did not receive 6\% (70/0.5) or 6\% (130/0.4) HES for anesthesia management before or after CPB. Multivariable logistic regression and propensity matching analysis were performed to examine whether use of HES is associated with postoperative AKI. Outcomes comparing patients receiving HES $\geq 1000 \mathrm{~mL}$ and $<1000 \mathrm{~mL}$ were also compared.

Results: Data from 1976 patients were reviewed. All patients received 70/0.5 HES as a part of the priming solution for CPB. The incidence of postoperative AKI was $28.2 \%$ in patients who received HES and $26.0 \%$ in patients who did not $(p=0.33)$. In multivariable analysis, there was no correlation between the use of HES and the incidence of AKI (odds ratio $0.87,95 \% \mathrm{Cl} 0.30-2.58, p=0.81$ ). Propensity matching showed that the incidence of AKI was not significantly different between 481 patients administered with HES and 962 patients (26.6\% vs. 26.9\%, $p=0.95$ ) who did not receive HES for anesthesia management. However, peak creatinine levels, needed for renal replacement therapy, and in-hospital mortality were higher, and 28-day hospital-free days were lower in patients receiving HES $\geq 1000 \mathrm{~mL}$ than those receiving HES $<1000 \mathrm{~mL}(p<0.05)$.

Conclusions: Intraoperative use of HES was not associated with postoperative AKI following CPB. However, administration of large volumes of HES may be associated with kidney-related adverse clinical outcomes.

Keywords: Hydroxyethyl starch, Intraoperative, AKI, Kidney damage, Cardiothoracic surgery

\footnotetext{
* Correspondence: msanui@jichi.ac.jp; msanui@mac.com

'Department of Anesthesiology and Critical Care Medicine, Jichi Medical University Saitama Medical Centre, 1-847 Amanumacho, Omiya-ku, Saitama City, Saitama 330-8503, Japan

Full list of author information is available at the end of the article
} 


\section{Background}

Maintaining intravascular volume by fluid administration is essential to maintain stable hemodynamic status, but optimal perioperative fluid management including the types and the amount of fluid infused is a matter of continuing debate. Colloid solutions are often used with the expectation of maintaining intravascular volume and improving perioperative outcomes compared to crystalloids (Thompson and Walton 1964). However, a substantial number of studies failed to show clinical benefits of colloids compared with crystalloids (Glover et al. 2014). Several studies showed that colloid solutions are harmful, including detrimental effects of hydroxyethyl starch (HES) on kidney function and overall prognosis. The deleterious effects of HES on kidney function have been well documented in critically ill (Myburgh et al. 2012) and septic patients (Perner et al. 2012) in the intensive care unit (ICU).

However, whether the intraoperative use of HES has a detrimental effect on postoperative kidney function is controversial. A meta-analysis of 19 randomized controlled trials (Gillies et al. 2014) comparing intraoperative use of HES with other fluid solutions concluded that HES is not associated with an increase in mortality during hospitalization or an increased need for renal replacement therapy (RRT). However, another systematic review suggested an increased risk of postoperative renal damage with the intraoperative use of HES (Ishihara 2014).

To clarify these discrepant results, we hypothesized that the intraoperative use of HES solution has a detrimental effect on postoperative kidney function after cardiopulmonary bypass (CPB). The association between intraoperative administration of HES, either 6\% (130/ $0.4)$ or $6 \%(70 / 0.5)$ solution, and postoperative acute kidney injury (AKI) defined by the Kidney Disease Improving Global Outcome (KDIGO) criteria, was analyzed in patients who underwent $\mathrm{CPB}$ during cardiothoracic surgery.

\section{Materials and methods}

Institutional Review Board (IRB) approval was obtained, and the need for informed consent was waived due to the nature of the study. All patients who underwent cardiothoracic surgery at Jichi University Saitama Medical Centre between 2007 and 2014 were included in this study. Patients under 18 years old, those who were undergoing RRT at the time of surgery, and those who did not have serum creatinine levels measured within 6 weeks before surgery were excluded. Patients who had missing data were excluded to maintain the quality of the study.

An electronic medical record maintains all patient information during the hospital stay (COSMOS, IBM Japan, Ltd., Japan,). Separate electronic medical record systems record perioperative information including information associated with anesthesia (ORSYS, Philips Electronics Japan, Ltd., Japan) and postoperative ICU information (PIMS, Philips Electronics Japan, Ltd., Japan). All patient information in the ORSYS and PIMS systems were extracted through Vi-Pros (DOWELL Co., Ltd., Japan) data mining software, except perioperative laboratory data and patient demographic information from COSMOS. Patient preoperative characteristics including age, gender, body mass index, emergency surgery, comorbidities (hypertension, diabetes mellitus, chronic obstructive pulmonary disease, and chronic heart failure), American Society of Anesthesiologists classification, preoperative use of angiotensin-converting-enzyme inhibitors/angiotensin receptor blockers, atrial fibrillation, and preoperative serum creatinine level within 6 weeks prior to surgery were collected as baseline information. Intraoperative data extracted included the type of surgery, operative time, cardiopulmonary bypass (CPB) time, maximum/total duration with a mean blood pressure lower than $65 \mathrm{mmHg}$, estimated blood loss, intraoperative urinary output, crystalloid and 6\% (70/0.5) HES (Hespander; Fresenius Kabi Japan Inc., Tokyo, Japan and Salinhes ${ }^{\oplus}$; Fresenius Kabi Japan Inc., Tokyo, Japan) and 6\% (130/0.4) HES (Voluven ${ }^{\circ}$; Fresenius Kabi Japan Inc., Tokyo, Japan) administered, and volume of blood transfused. The type and amount of transfusion was left to the anesthesiologists' discretion. Postoperative parameters including maximum serum creatinine level within 7 days after surgery, need for RRT, ICU length of stay, hospital length of stay, and in-hospital mortality were extracted. Postoperatively, no patients received HES in the ICU, since avoiding HES administration is a part of our routine practice.

Patients were divided into two groups for review: a group who received any type of HES solution (the HES group) and others who did not receive HES (the control group) before or after CPB during surgery. Since $500 \mathrm{~mL}$ of Salinhes ${ }^{\oplus}$ was routinely used as a part of the priming solution for cardiopulmonary bypass, all study patients received an identical (i.e., $500 \mathrm{~mL}$ ) volume of Salinhes ${ }^{\oplus}$.

Multivariable logistic regression analysis was performed to estimate the effect of each type of HES solution (Hespander ${ }^{\oplus}$ Salinhes ${ }^{\oplus}$, and Voluven ${ }^{\oplus}$ ) on the incidence of postoperative AKI using preoperative and intraoperative patient demographic parameters (as shown in Table 4). Each administration of $500 \mathrm{~mL}$ of Hespander $^{\oplus}$, Salinhes ${ }^{\oplus}$, and Voluven ${ }^{\oplus}$ was used as an independent covariate to clarify each product's effect on the incidence of postoperative AKI. To reduce the impact of selection bias, propensity score matching analysis was performed. The propensity score to receive HES before or after $\mathrm{CPB}$ was calculated using a logistic regression model using variables including preoperative and 
intraoperative patient demographic parameters (age, gender, body mass index, emergency surgery, comorbidities, American Society of Anesthesiologists classification, preoperative use of angiotensin-converting-enzyme inhibitors/angiotensin receptor blockers, preoperative serum creatinine levels, operative time, CPB time, estimated blood loss, intraoperative urinary output, crystalloid administrated, and volume of blood transfused). Each patient who received HES was matched to two patients who did not receive HES without replacement, using the method of Sekhon et al. with a caliper (Sekhon 2011).

The primary outcome of this study was the incidence of AKI within 7 days after surgery defined by the KDIGO criteria. Only creatinine criteria were applied due to the lack of data for postoperative urine volume. Secondary outcomes included the need for RRT, ICU length of stay, and hospital mortality. To examine the dose-dependent effects of HES, we divided all patients before propensity matching into two groups (those who received HES $1000 \mathrm{~mL}$ or more and those who received less than $1000 \mathrm{~mL}$ ) and compared the incidence of AKI, the need for RRT, ICU length of stay, and hospital mortality between the two groups. The cost of the solutions (HES and crystalloids) administered to each patient during surgery was determined and compared between the two groups.

\section{Statistical analysis}

Data are expressed as mean and standard deviation or median and $25 \%$ and $75 \%$ percentiles, as appropriate. The Mann-Whitney $U$ test was used to compare continuous variables and the $\chi^{2}$ test was used to compare nominal variables. Multivariable logistic regression analysis was performed to estimate the effects of each type of HES solution (Hespander ${ }^{\oplus}$, Salinhes ${ }^{\oplus}$, and Voluven ${ }^{\circ}$ ) on the incidence of postoperative AKI using preoperative and intraoperative patient parameters (as listed above).

To compare patients who did or did not receive HES, standardized differences were calculated. Standardized differences less than $10 \%$ denote a negligible imbalance between the groups. Outcomes were compared using the Mann-Whitney $U$ test for continuous variables and $\chi^{2}$ test for nominal variables. All statistical analyses were performed with EZR (Saitama Medical Centre, Jichi Medical University, Saitama, Japan), which is a graphical user interface for $\mathrm{R}$ (The $\mathrm{R}$ Foundation for Statistical Computing, Vienna, Austria) (Kanda 2013).

\section{Results}

A total of 2158 patients who underwent cardiothoracic surgery from 2007 through 2014 were identified using the Vi-Pros ${ }^{\oplus}$ software. After applying exclusion criteria, 1976 patients were included in this study (Fig. 1) and
536 patients (27.1\%) had HES administration with a mean volume of $719 \mathrm{~mL}$ and a median of $500 \mathrm{~mL}(500$ $1000 \mathrm{~mL}$, as $25 \%$ and $75 \%$ percentiles) for anesthesia management. Preoperative patient characteristics are shown in Table 1. Patients who received HES were less likely to be male and less likely to be taking angiotensinconverting-enzyme inhibitor medications preoperatively. There was no difference in preoperative serum creatinine levels between the two groups.

Outcomes are shown in Tables 2 and 3. The postoperative incidence of AKI was not different between the groups $(28.2 \%$ in the HES group and $26.0 \%$ in the control group, $p=0.33$ ). The need for RRT and hospital mortality was similar in both groups, while the ICU length of stay was longer in the HES group.

Multivariable analysis revealed that atrial fibrillation, body mass index, estimated blood loss (intervals of 100 $\mathrm{mL}$ ), and FFP transfused (by units, $120 \mathrm{~mL}$ ) were significantly associated with the incidence of postoperative AKI (Table 4). There was no correlation between the use of any of the three HES solutions studied and the incidence of AKI (Hespander, odds ratio 1.94, 95\% CI $0.43-8.72, p=0.39$; Salinhes ${ }^{\circ}$, odds ratio $0.74,95 \%$ CI $0.02-35.7, p=0.88$; Voluven ${ }^{\circ}$, odds ratio $0.87,95 \% \mathrm{CI}$ $0.30-2.58, p=0.81$, respectively).

A total of 481 patients in the HES group were matched to the 962 patients in the control group using propensity scoring. Preoperative and intraoperative patient characteristics were similar in the two groups. (Table 5).

Outcomes are shown in Table 6. The incidence of AKI within 7 days after surgery in the HES group was not significantly different from the control group $(26.6 \%$ vs. $26.9 \%, p=0.95)$. The need for postoperative RRT $(5.0 \%$ in the HES group and $4.5 \%$ in the control group, $p=$ $0.757)$ and hospital mortality (3.3\% in the HES group and $2.8 \%$ in the control group, $p=0.702$ ) were not significantly different between the two groups. ICU length of stay was longer (3 (3-5) days vs. $3(3-4)$ days, $p=$ 0.0301 ) in the HES group than in the control group.

To investigate the dose-dependent effects of HES, we compared the outcomes between patients who received $1000 \mathrm{~mL}$ or more of HES and those who received less than $1000 \mathrm{~mL}$ of HES before or after CPB (Table 3). Peak serum creatinine levels $(p=0.038)$, need for RRT $(p=0.017)$, and in-hospital mortality $(p=0.017)$ were higher, and 28-day hospital-free days was less in patients receiving HES $\geq 1000 \mathrm{~mL}$ than in those receiving HES < $1000 \mathrm{~mL}$. The mean cost of fluid administration for each patient in the HES group was $2443 \pm 1136$ yen (corresponding to $21.6 \pm 10.0$ US dollars), whereas the control group was $1214 \pm 482$ yen (corresponding to $10.7 \pm 4.3$ US dollars, with a conversion rate of 113.25 yen/dollar) $(p<0.001)$. 


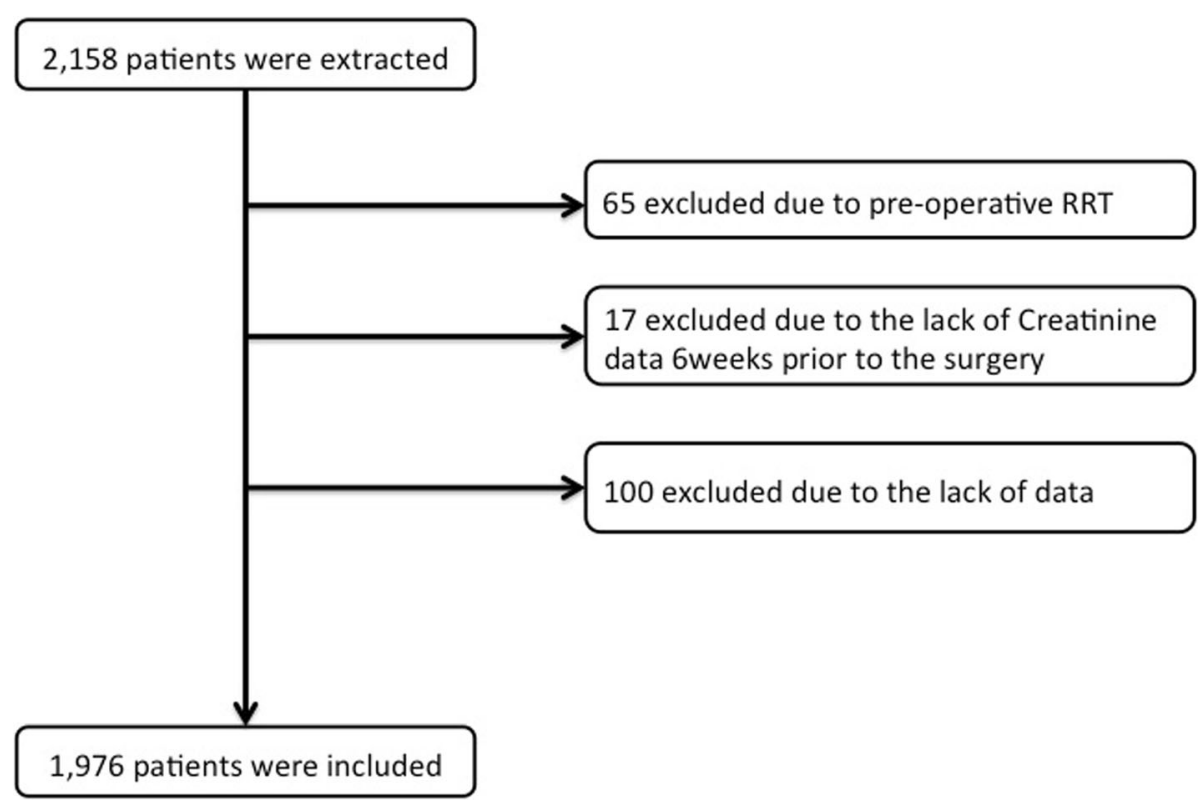

Fig. 1 Study patient flow diagram

\section{Discussion}

This study evaluated the effect of intraoperative HES administration on postoperative kidney function. Propensity matching was performed to adjust for selection biases, showing that HES administration is not associated with an increase in the incidence of postoperative AKI. However, compared to HES $<1000 \mathrm{~mL}$, administration of HES $\geq 1000 \mathrm{~mL}$ may be associated with worse postoperative outcomes including significantly higher serum creatinine levels, greater need for RRT, higher inhospital mortality, and lower 28-day hospital-free days.

Compared to previous studies examining the impact of HES administration on the incidence of postoperative AKI, the present study included a greater number of patients. Only a few studies have evaluated renal function after administration of HES 70/0.5 (Endo et al. 2012), a widely used solution in Japan. This study evaluated the effects of intraoperative administration of HES 70/0.5 as well as HES 130/0.4 on postoperative kidney function.

On a molecular level, HES is believed to cause kidney injury due to its high oncotic pressure, which can directly decrease glomerular filtration, resulting in interstitial inflammatory changes (Schortgen and Brochard 2009; Hüter et al. 2009). From a clinical perspective, the CHEST study (Myburgh et al. 2012) showed that administration of HES was related to an increase in the need for RRT, supporting previous studies. The 6S study (Perner et al. 2012) also supports the possibility of a deleterious effect of HES at the molecular level, showing a relationship between administration of HES and 90-day mortality and the need for RRT.
Vast majority (90.7\%) of patients who received any type of HES were administered with HES 70/0.5 in the operating room in the present study, while all participants were administered with HES 130/0.7 in the ICU in the previous studies (Myburgh et al. 2012; Perner et al. 2012). Endo et al. (Endo et al. 2012) investigated the relationship between the intraoperative sole use of HES 70/0.5 in mixed surgical patients including cardiac surgery and the incidence of AKI, showing no correlation. In Endo's study (Endo et al. 2012), lower molecular weight HES (70/0.5) might have led to less accumulation in the kidney with fewer patients developing AKI, while in the current study, a larger amount of HES administration $(\geq 1000 \mathrm{ml})$ resulted in a greater incidence of needing RRT and higher peak serum creatinine levels (Table 3). Either additional administration of higher molecular weight HES (130/0.7) or the patient characteristics (i.e., cardiac surgical patients) might have affected the results.

In the present study, the use of HES had no effect on the total volume of fluid administered as shown in previous studies (Perner et al. 2012; Lagny et al. 2015). In a study by Lagny (Lagny et al. 2015), the cumulative fluid balance over $48 \mathrm{~h}$ was $1077 \pm 1698$ in the crystalloid group and $1563 \pm 1844$ in the HES groups, a significantly greater volume of fluid administered to the HES group. Based on the results showing no reduction in total fluid administration along with the potential adverse effects in patients receiving a higher amount of HES, there may be no clinical benefit when using this small amount of HES. Since the cost of the fluid administered to the HES group was approximately twice as much as fluid for the 
Table 1 Demographic characteristics of study patients who did or did not receive HES before or after cardiopulmonary bypass

\begin{tabular}{|c|c|c|c|}
\hline & HES & Control & Standardized difference (\%) \\
\hline \multicolumn{4}{|l|}{ Preoperative parameters } \\
\hline Number of patients & 536 & 1440 & \\
\hline Age (years) & $65.8 \pm 13.0$ & $66.9 \pm 12.0$ & -1.46 \\
\hline Male gender & $338(63.1 \%)$ & $782(54.3 \%)$ & 18.2 \\
\hline Body mass index $\left(\mathrm{kg} / \mathrm{m}^{2}\right)$ & $22.7 \pm 3.8$ & $23.2 \pm 3.8$ & 7.10 \\
\hline Preoperative serum creatinine $(\mathrm{mg} / \mathrm{dL})$ & $1.00 \pm 0.81$ & $0.92 \pm 0.39$ & -37.7 \\
\hline Emergency & $202(37.7 \%)$ & $527(36.6 \%)$ & 2.33 \\
\hline \multicolumn{4}{|l|}{ Preoperative comorbidities } \\
\hline Hypertension & $328(61.2 \%)$ & $859(59.7 \%)$ & 3.22 \\
\hline Diabetes mellitus & 79 (14.7\%) & $223(15.5 \%)$ & -2.91 \\
\hline Chronic obstructive pulmonary disease & $12(2.2 \%)$ & $31(2.2 \%)$ & 2.00 \\
\hline Chronic heart failure & $214(39.9 \%)$ & $598(41.5 \%)$ & -3.32 \\
\hline Atrial fibrillation & $130(24.3 \%)$ & $320(22.2 \%)$ & 5.70 \\
\hline \multicolumn{4}{|l|}{ American Society of Anesthesiologists classification } \\
\hline 1 & $11(2.1 \%)$ & $24(1.7 \%)$ & \\
\hline 2 & $329(61.4 \%)$ & $779(54.1 \%)$ & \\
\hline 3 & $159(30.0 \%)$ & $523(36.3 \%)$ & \\
\hline 4 & $31(5.8 \%)$ & $107(7.4 \%)$ & \\
\hline 5 & $6(1.1 \%)$ & $7(0.5 \%)$ & \\
\hline \multicolumn{4}{|l|}{ Preoperative medications } \\
\hline Angiotensin-converting-enzyme inhibitors & $105(19.6 \%)$ & $210(14.6 \%)$ & 17.7 \\
\hline Angiotensin II receptor blockers & $187(34.9 \%)$ & $466(32.4 \%)$ & 5.67 \\
\hline \multicolumn{4}{|l|}{ Intraoperative parameters } \\
\hline HES $(m L)$ & $719 \pm 422$ & - & \\
\hline Hespander $^{\circledast}(\mathrm{mL})$ & $15 \pm 105$ & & \\
\hline Salinhes ${ }^{\oplus}(\mathrm{mL})$ & $655 \pm 467$ & & \\
\hline Voluven $^{\circledast}(\mathrm{mL})$ & $49 \pm 183$ & & \\
\hline Crystalloids (mL) & $2549 \pm 1611$ & $2559 \pm 1090$ & -0.00025 \\
\hline Red blood cells (mL) & $547 \pm 1074$ & $494 \pm 763$ & 0.0123 \\
\hline Fresh frozen plasma $(\mathrm{mL})$ & $486 \pm 814$ & $412 \pm 592$ & 0.0292 \\
\hline Platelet concentrates $(\mathrm{mL})$ & $119 \pm 210$ & $111 \pm 190$ & 0.0423 \\
\hline Autotransfusion (mL) & $134 \pm 292$ & $76 \pm 223$ & 0.174 \\
\hline Estimated blood loss (mL) & $807 \pm 889$ & $649 \pm 605$ & 0.0547 \\
\hline Urinary outputs (mL) & $1412 \pm 880$ & $1338 \pm 815$ & 0.0207 \\
\hline Operative time (min) & $372 \pm 144$ & $354 \pm 110$ & 0.220 \\
\hline Cardiopulmonary bypass time (min) & $177 \pm 79$ & $168 \pm 59$ & 0.360 \\
\hline Longest interval of mABP < 65 (min) & $70 \pm 57$ & $66 \pm 53$ & 0.279 \\
\hline Total mABP < 65 duration (min) & $222 \pm 124$ & $211 \pm 108$ & 0.160 \\
\hline \multicolumn{4}{|l|}{ Operative procedure } \\
\hline On-pump CABG & $8(1.5 \%)$ & $20(1.4 \%)$ & \\
\hline Valve surgery & $291(54.3 \%)$ & $734(51.0 \%)$ & \\
\hline Valve + CABG & $36(6.7 \%)$ & $140(9.7 \%)$ & \\
\hline Major aortic surgery & $172(32.1 \%)$ & $461(32.0 \%)$ & \\
\hline Other & $29(5.4 \%)$ & $85(5.9 \%)$ & \\
\hline
\end{tabular}


Table 2 Outcomes of patients who did or did not receive HES before or after cardiopulmonary bypass

\begin{tabular}{llll}
\hline & HES $(n=536)$ & Control $(n=1440)$ & $p$ value \\
\hline AKl incidents & $151(28.2 \%)$ & $374(26.0 \%)$ & 0.33 \\
AKI stage & & & \\
1 & $93(17.4 \%)$ & $229(15.9 \%)$ & \\
2 & $20(3.7 \%)$ & $53(3.7 \%)$ & \\
3 & $38(7.1 \%)$ & $92(6.4 \%)$ & \\
$\begin{array}{l}\text { Peak serum creatinine } \\
\text { (mg/dL) }\end{array}$ & $0.96(0.77-1.27)$ & $0.93(0.71-1.35)$ & 0.28 \\
$\begin{array}{l}\text { Need for RRT } \\
\text { ICU length of stay (days) }\end{array}$ & $3(3-5)$ & $3(3-4)$ & 0.73 \\
$\begin{array}{l}\text { 28-day hospital free } \\
\text { days (days) }\end{array}$ & $11(4-14)$ & $12(6-15)$ & 0.0079 \\
Hospital mortality & $22(4.1 \%)$ & $38(2.6 \%)$ & 0.060 \\
\hline
\end{tabular}

Data are expressed as medians with 25th to 75th percentiles or percentages HES hydroxyethyl starch, AKI acute kidney injury, RRT renal replacement therapy, ICU intensive care unit

control group, it is difficult to rationalize the deliberate use of HES during cardiac surgery.

We acknowledge several limitations in the current study. First, this is a retrospective study, and unrecognized confounding factors could affect the results. To minimize the effect of confounding factors, we performed propensitymatched analysis including a wide range of preoperative and intraoperative variables associated with the use of HES. Second, since this is a single-center study, external validity may be limited. However, the inclusion of a large number of patients (approximately 2000) undergoing a wide range of operative procedures over a relatively long period (8 years) may partially overcome the limitation. Third, all

Table 3 Outcomes of patients who received HES $\geq 1000 \mathrm{~mL}$ or $<1000 \mathrm{~mL}$

\begin{tabular}{llll}
\hline & HES $\geq 1000 \mathrm{~mL}$ & HES $<1000 \mathrm{~mL}$ & $p$ value \\
\hline Number of patients & 179 & 357 & 0.22 \\
AKI incidents & $57(31.8 \%)$ & $94(26.3 \%)$ & \\
AKI stage & $35(19.6 \%)$ & $58(16.2 \%)$ & \\
1 & $3(1.7 \%)$ & $17(4.8 \%)$ & \\
2 & $19(10.6 \%)$ & $19(5.3 \%)$ & 0.038 \\
3 & $1.01(0.81-1.33)$ & $0.94(0.75-1.25)$ & 0.017 \\
$\begin{array}{l}\text { Peak serum creatinine } \\
\text { (mg/dL) }\end{array}$ & $16(8.9 \%)$ & $14(3.9 \%)$ & 0.27 \\
RRT requirement & $4(3-5)$ & $3(3-5)$ & 0.032 \\
ICU length of stay (days) & $10(0-14)$ & $12(5-14)$ & 0.017 \\
$\begin{array}{l}\text { 28-day hospital free } \\
\text { days (days) }\end{array}$ & $13(7.3 \%)$ & $9(2.5 \%)$ & \\
Hospital mortality & & & \\
\hline
\end{tabular}

Data are expressed as medians with 25th to 75th percentiles or percentages $H E S$ hydroxyethyl starch, $A K I$ acute kidney injury, $R R T$ renal replacement therapy, ICU intensive care unit
Table 4 Preoperative and intraoperative factors associated with postoperative acute kidney injury by multivariable logistic regression analysis

\begin{tabular}{|c|c|c|}
\hline & $\begin{array}{l}\text { Odds ratio } \\
\text { (95\% confidence interval) }\end{array}$ & $\begin{array}{l}p \\
\text { value }\end{array}$ \\
\hline Age & $1.04(0.99-1.10)$ & 0.13 \\
\hline Male gender & $2.42(0.80-7.33)$ & 0.12 \\
\hline Body mass index (kg/m2) & $1.19(1.02-1.39)$ & 0.028 \\
\hline Hypertension & $2.25(0.75-6.73)$ & 0.15 \\
\hline Diabetes mellitus & $1.19(0.24-5.91)$ & 0.83 \\
\hline $\begin{array}{l}\text { Chronic obstructive pulmonary } \\
\text { disease }\end{array}$ & $1.00(0.99-1.02)$ & 0.22 \\
\hline Chronic heart failure & $0.59(0.18-1.95)$ & 0.38 \\
\hline $\begin{array}{l}\text { American Society of } \\
\text { Anesthesiologists classification }\end{array}$ & $1.73(0.85-3.49)$ & 0.13 \\
\hline $\begin{array}{l}\text { Angiotensin-converting-enzyme } \\
\text { inhibitors }\end{array}$ & $0.91(0.18-4.68)$ & 0.91 \\
\hline Angiotensin receptor blockers & $0.91(0.27-3.02)$ & 0.87 \\
\hline Atrial fibrillation & $6.18(1.71-22.3)$ & 0.0054 \\
\hline Emergency & $2.48(0.76-8.10)$ & 0.13 \\
\hline Operative time (hour) & $1.31(0.76-2.27)$ & 0.33 \\
\hline Cardiopulmonary bypass time (min) & $1.31(0.76-2.27)$ & 0.55 \\
\hline Estimated blood loss (/100 mL) & $1.16(1.03-1.30)$ & 0.011 \\
\hline Urinary output & $0.93(0.85-1.01)$ & 0.068 \\
\hline Crystalloid (/500 mL) & $0.77(0.57-1.04)$ & 0.084 \\
\hline Hespander ${ }^{\circledast}(/ 500 \mathrm{~mL})$ & $2.05(0.45-9.25)$ & 0.35 \\
\hline Salinhes ${ }^{\circledast}(/ 500 \mathrm{~mL})$ & $0.53(0.01-34.5)$ & 0.77 \\
\hline Voluven $^{\oplus}(/ 500 \mathrm{~mL})$ & $0.88(0.31-2.53)$ & 0.81 \\
\hline Red blood cells (/unit) & $1.08(0.89-1.30)$ & 0.44 \\
\hline Fresh frozen plasma (/unit) & $0.88(0.79-0.99)$ & 0.032 \\
\hline Platelet concentrates (/unit) & $1.01(0.95-1.07)$ & 0.73 \\
\hline Autotransfusion (/unit) & $0.78(0.23-2.63)$ & 0.68 \\
\hline
\end{tabular}

patients were given $500 \mathrm{~mL}$ of $6 \%$ HES $(0.7 / 0.5)$ as a priming volume for $\mathrm{CPB}$, which could obscure potential differences between the groups. We intended to investigate the effects of HES solutions used before or after CPB, when anesthesiologists are in charge of the fluid and hemodynamic management. In the present study, the average of $719 \mathrm{~mL}$ of HES was administered in the HES group, while in previous studies, a similar dose was administered in the HES groups with mixed results (Ishihara 2014; Endo et al. 2012). The present study suggests a potential harm by the use of a larger amount of either HES solution (70/0.5 or 130/0.4), which may add another relevant information for anesthesiologists. Fourth, for data analysis, patients given either HES 70/0.5 or HES 130/0.4 were allocated to a single "HES-administered" group since the number of patients who received HES 130/0.4 was limited, which could affect the results of the analysis. Fifth, AKI may appear after the initial 7 days of ICU stays and may be missed if the data collection 
Table 5 Propensity-matched comparison of study patients who did or did not receive HES before or after cardiopulmonary bypass

\begin{tabular}{|c|c|c|c|}
\hline & HES & Control & Standardized difference \\
\hline \multicolumn{4}{|l|}{ Preoperative parameters } \\
\hline Number of patients & 481 & 962 & \\
\hline Age (years) & $65.9 \pm 13.2$ & $66.2 \pm 12.2$ & 2.74 \\
\hline Male gender & $292(60.7 \%)$ & $581(60.4 \%)$ & 0.65 \\
\hline Body mass index $\left(\mathrm{kg} / \mathrm{m}^{2}\right)$ & $23.1 \pm 3.8$ & $22.9 \pm 3.2$ & 0.49 \\
\hline Preoperative creatinine (mg/dL) & $0.92 \pm 0.40$ & $0.93 \pm 0.40$ & 2.17 \\
\hline Emergency & $180(37.4 \%)$ & $369(38.4 \%)$ & -1.99 \\
\hline \multicolumn{4}{|l|}{ Preoperative comorbidities } \\
\hline Hypertension & $289(60.0 \%)$ & $587(61.0 \%)$ & -1.96 \\
\hline Diabetes mellitus & $68(14.1 \%)$ & $142(14.8 \%)$ & -2.52 \\
\hline Chronic obstructive pulmonary disease & $12(2.5 \%)$ & $23(2.4 \%)$ & 2.18 \\
\hline Chronic heart failure & $192(39.9 \%)$ & $383(39.8 \%)$ & 0.22 \\
\hline Atrial fibrillation & $113(23.5 \%)$ & $232(24.1 \%)$ & -1.72 \\
\hline \multicolumn{4}{|l|}{ American Society of Anesthesiologists Classification } \\
\hline 1 & $10(2.1 \%)$ & $20(2.1 \%)$ & \\
\hline 2 & $296(61.5 \%)$ & $553(57.5 \%)$ & \\
\hline 3 & $143(29.7 \%)$ & $314(32.6 \%)$ & \\
\hline 4 & $26(5.4 \%)$ & $72(7.5 \%)$ & \\
\hline 5 & $6(1.2 \%)$ & $3(0.3 \%)$ & \\
\hline \multicolumn{4}{|l|}{ Preoperative medication } \\
\hline Angiotensin-converting-enzyme inhibitors & $82(17.0 \%)$ & $170(17.7 \%)$ & -2.17 \\
\hline Angiotensin II receptor blockers & $168(34.9 \%)$ & $341(35.4 \%)$ & -1.14 \\
\hline \multicolumn{4}{|l|}{ Intraoperative parameters } \\
\hline HES (mL) & $692 \pm 387$ & - & \\
\hline Hespander $^{\otimes}(\mathrm{mL})$ & $14 \pm 104$ & & \\
\hline Salinhes ${ }^{\oplus}(\mathrm{mL})$ & $627 \pm 432$ & & \\
\hline Voluven $^{\circledast}(\mathrm{mL})$ & $50 \pm 186$ & & \\
\hline Crystalloids (mL) & $2524 \pm 1627$ & $2553 \pm 1129$ & 2.06 \\
\hline Red blood cells (mL) & $457 \pm 959$ & $511 \pm 858$ & 5.84 \\
\hline Fresh frozen plasma $(\mathrm{mL})$ & $392 \pm 628$ & $440 \pm 653$ & 7.60 \\
\hline Platelet concentrates (mL) & $102 \pm 193$ & $112 \pm 192$ & 4.99 \\
\hline Estimated blood loss (mL) & $669 \pm 656$ & $715 \pm 681$ & 6.82 \\
\hline Urinary outputs (mL) & $1387 \pm 884$ & $1391 \pm 846$ & 0.48 \\
\hline Operative time (min) & $356 \pm 124$ & $364 \pm 116$ & 7.16 \\
\hline Cardiopulmonary bypass time (min) & $170 \pm 67$ & $173 \pm 61$ & 5.53 \\
\hline Longest interval of mABP < 65 (min) & $66 \pm 54$ & $67 \pm 53$ & 1.92 \\
\hline Total mABP < 65 duration (min) & $210 \pm 107$ & $215 \pm 114$ & 5.09 \\
\hline \multicolumn{4}{|l|}{ Operation procedures } \\
\hline On-pump CABG & $8(1.7 \%)$ & $14(1.5 \%)$ & \\
\hline Valve surgeries & $261(54.3 \%)$ & $489(50.8 \%)$ & \\
\hline Valve + CABG & $34(7.1 \%)$ & $93(9.7 \%)$ & \\
\hline Major aortic surgeries & $152(31.6 \%)$ & $316(32.8 \%)$ & \\
\hline Others & $26(5.4 \%)$ & $50(5.2 \%)$ & \\
\hline
\end{tabular}


Table 6 Propensity-matched comparison outcomes in patients who did or did not receive HES before or after cardiopulmonary bypass

\begin{tabular}{llll}
\hline & HES $(n=481)$ & Control $(n=962)$ & $p$ value \\
\hline AKI incidents & $128(26.6 \%)$ & $259(26.9 \%)$ & 0.95
\end{tabular}

AKI stage

\begin{tabular}{clll}
1 & $81(16.8 \%)$ & $162(16.8 \%)$ & \\
2 & $17(3.5 \%)$ & $42(4.4 \%)$ & \\
3 & $30(6.2 \%)$ & $55(5.7 \%)$ & \\
Peak creatinine (mg/dL) & $0.94(0.76-1.26)$ & $0.95(0.74-1.35)$ & 0.878 \\
Need for RRT & $24(5.0 \%)$ & $43(4.5 \%)$ & 0.757 \\
ICU length of stay (days) & $3(3-5)$ & $3(3-4)$ & 0.0301 \\
$\begin{array}{l}\text { 28-day hospital free } \\
\text { days (days) }\end{array}$ & $11(5-14)$ & $12(5-15)$ & 0.293 \\
Hospital mortality & $16(3.3 \%)$ & $27(2.8 \%)$ & 0.702 \\
\hline
\end{tabular}

Data are expressed as medians with 25th to 75th percentiles or percentages HES hydroxyethyl starch, $A K I$ acute kidney injury, $R R T$ renal replacement therapy, ICU intensive care unit

on AKI is limited to the initial 7 days. However, we focused solely on the effects of intraoperative use of HES and intended to exclude the postoperative factors potentially affecting renal function. A previous study examining the effects of intraoperative use of HES on postoperative renal function also had the identical study period (Endo et al. 2012).

According to this retrospective study, administration of HES to patients undergoing cardiothoracic surgery before or after $\mathrm{CPB}$ was not associated with the incidence of postoperative AKI. However, a larger amount of HES may be associated with worse clinical outcomes. A large-scale randomized controlled study will be needed to establish the efficacy and safety of intraoperative administration of HES.

\section{Acknowledgements}

Not applicable.

\section{Authors' contributions}

WM and MS planned the study and contributed to the analysis of data and manuscript preparation. YS contributed to the data analysis. AKL contributed to developing the manuscript. All authors contributed to the data correction and read and approved the final manuscript.

\section{Funding}

Not applicable.

\section{Availability of data and materials}

The datasets used and/or analyzed during the current study are available from the corresponding author on reasonable request.

\section{Ethics approval and consent to participate}

This study obtained exemption from Institutional Review Board (IRB) of Jichi Medical University, Saitama Medical Centre, and the need for informed consent was waived due to the nature of the study.

\section{Consent for publication}

Not applicable.

\section{Competing interests}

The authors declare that they have no competing interests.

\section{Author details}

${ }^{1}$ Department of Anesthesiology and Critical Care Medicine, Jichi Medical University Saitama Medical Centre, 1-847 Amanumacho, Omiya-ku, Saitama City, Saitama 330-8503, Japan. ${ }^{2}$ Data Science Centre, Jichi Medical University, 3311-1 Yakushiji, Shimotsuke, Tochigi 329-0498, Japan. ${ }^{3}$ Department of Surgery, Jichi Medical University, 3311-1 Yakushiji, Shimotsuke City, Tochigi 329-0498, Japan.

Received: 20 June 2019 Accepted: 9 October 2019

Published online: 31 October 2019

\section{References}

Endo A, Uchino S, Iwai K, Saito K, Sanui M, Takinami M, et al. Intraoperative hydroxyethyl starch 70/0.5 is not related to acute kidney injury in surgical patients: retrospective cohort study. Anesth. Analg. 2012;115: 1309-14.

Gillies MA, Habicher M, Jhanji S, Sander M, Mythen M, Hamilton M, et al. Incidence of postoperative death and acute kidney injury associated with i.v. $6 \%$ hydroxyethyl starch use: systematic review and meta-analysis. Br. J. Anaesth. 2014;112:25-34.

Glover PA, Rudloff E, Kirby R. Hydroxyethyl starch: a review of pharmacokinetics, pharmacodynamics, current products, and potential clinical risks, benefits, and use. J Vet Emerg Crit Care. 2014;24:642-61.

Hüter L, Simon T-P, Weinmann L, Schuerholz T, Reinhart K, Wolf G, et al. Hydroxyethylstarch impairs renal function and induces interstitial proliferation, macrophage infiltration and tubular damage in an isolated renal perfusion model. Crit Care. 2009;13:R23.

Ishihara $\mathrm{H}$. Kidney function after the intraoperative use of $6 \%$ tetrastarches (HES 130/0.4 and 0.42). J Anesth. 2014;28:249-56.

Kanda Y. Investigation of the freely available easy-to-use software 'EZR' for medical statistics. Bone Marrow Transplant. 2013;48:452-8.

Lagny M-G, Roediger L, Koch J-N, Dubois F, Senard M, Donneau A-F, et al. Hydroxyethyl starch 130/0.4 and the risk of acute kidney injury after cardiopulmonary bypass: a single-center retrospective study. J. Cardiothorac. Vasc. Anesth; 2015;30:0-22.

Myburgh JA, Finfer S, Bellomo R, Billot L, Cass A, Gattas D, et al. Hydroxyethyl starch or saline for fluid resuscitation in intensive care. N Engl J Med. 2012; 367:1901-11.

Perner A, Haase N, Guttormsen AB, Tenhunen J, Klemenzson G, Åneman A, et al. Hydroxyethyl starch 130/0.42 versus Ringer's acetate in severe sepsis. N. Engl. J Med. 2012;367:124-34.

Schortgen F, Brochard L. Colloid-induced kidney injury: experimental evidence may help to understand mechanisms. Crit Care. 2009;13:130.

Sekhon J. Multivariate and propensity score matching. J Stat Softw. 2011;42:52.

Thompson WL, Walton RP. Circulatory responses to intravenous infusions of hydroxyethyl starch solutions. J. Pharmacol. Exp Ther. 1964;146:359-64.

\section{Publisher's Note}

Springer Nature remains neutral with regard to jurisdictional claims in published maps and institutional affiliations.
Ready to submit your research? Choose BMC and benefit from:
- fast, convenient online submission
- thorough peer review by experienced researchers in your field
- rapid publication on acceptance
- support for research data, including large and complex data types
- gold Open Access which fosters wider collaboration and increased citations
- maximum visibility for your research: over $100 \mathrm{M}$ website views per year
At BMC, research is always in progress.
Learn more biomedcentral.com/submissions 